\title{
Management of Ashwagandha root rot disease with fungicides, biocontrol agents and botanicals
}

\author{
R. P. S. Jetawat* and K. Mathur \\ Department of Plant Pathology, RCA, Maharana Pratap University of Agriculture and Technology, Udaipur, \\ (Rajasthan), INDIA \\ *Corresponding author. E-mail: jaitawat.ravindra@gmail.com
}

Received: June 18, 2015; Revised received: November 19, 2015; Accepted: February 29, 2016

\begin{abstract}
The experiment was conducted to study fungicides, biocontrol agents and botanicals for management of ashwagandha root rot disease. Ashwagandha root rot disease caused by two pathogen Fusarium solani and Rhizoctonia solani. In field trial, seed treatments with integration of fungicides, neem cake manure, neem oil and Trichoderma viride agent evaluated as seed treatments individually as well as in different combination of seed treatment and soil application of neem cake was found effective integrated treatment (ST SAAF + neem cake manure + $T$. viride) and soil application of neem cake manure@500g/plot showed minimum per cent root rot and maximum per cent germination and maximum yield of Ashwagandha as compared to their individual applications over the untreated control.
\end{abstract}

Keywords: Ashwagandha, Fusarium solani, Neem cake manure, Rhizoctonia solani and T. viride

\section{INTRODUCTION}

Ashwagandha (Withania somnifera), also known as Indian ginseng, belonging to the family Solanaceae, is an important ancient medicinal plant, used in the Indian traditional systems of medicine, Ayurveda and Unani. Ashwagandha roots and their extracts are used in preparation of herbal tea, powders, tablets and syrups which help in reducing arthritis, disability, fatigue, high cholesterol and stress, increase healing processes, have positive effect against impotence and also normalize the sugar content of the blood.

It grows well in dry and sub-tropical regions of India, Sri Lanka and Bangladesh. Rajasthan, Punjab, Haryana, Uttar Pradesh, Gujarat, Maharashtra and Madhya Pradesh are the major producing states of India. The estimated production of its roots in India is more than 1500 tonnes, while the annual requirement is about 7000 tonnes, necessitating increase in its cultivation and higher production. (Anonymous, 1976., Sharma, 2004 and Baghel et al 2010 ). The roots, leaves and fruits (berry) possess medicinal values due to alkaloids and steroidal lactones with anoides which is anti-Inflammatory (Anabalagan and Sadique, 1984), anti-arthritis (Begum and Sadique, 1988) and immunosuppressive activities (Singh and Kumar, 1998), antioxidant (Dhuley, 1998), immunomodulatory (Davis and Kuttan, 2000), antidepressant (Bhattacharya et al, 2000).

The pharmaceutical industries are mainly dependent upon the wild population of Ashwagandha for the supply of tuberous roots for forskolin and withafarin extraction. The root rot of ashwagandha [W. somnifera (L.) Dunal] is an important disease causing significant economic and yield losses. Fusarium solani is a widely distributed soil-borne fungus pathogenic to at least 111 plant species spanning over 87 genera. It causes root rot diseases on a wide variety of crops. Rhizoctonia solani is also a widespread and destructive fungal pathogen of many plant species. Different types of disease symptoms like damping off, root, crown and stem rot, sheath blight etc. are caused by the pathogen. In view of increasing importance of root rot of ashwagandha, the present study was undertaken to investigate the efficacy of fungicides, biocontrol agents and botanicals against the disease.

\section{MATERIALS AND METHODS}

Diseased roots of Ashwagandha ( $W$. somanifera) were collected from farmer's field of Udaipur and Rajasthan College of Agriculture, Udaipur.

Isolation, purification and identification of the pathogen: For isolation of the pathogen, small pieces of diseased roots were cut, washed in water and surface sterilized by dipping in 0.10 per cent mercuric chloride solution for 2 minutes followed by three washings in sterilized distilled water and plated on 2 per cent PDA plates aseptically. These were incubated at $25 \pm 2{ }^{\circ} \mathrm{C}$ in incubator for growth. Sub-cultures from peripheral growth were made on PDA slants.

The culture of Rhizoctonia was purified by single hyphal-tip method and that of Fusarium by single spore method using a dummy objective. The cultures were identified by comparing the morphological and 
culture characters described by Mordue (1988) for Rhizoctonia and Booth (1971) for Fusarium and were identified as Rhizoctonia solani and Fusarium solani.

Planting method and multiplication of $F$. solani and R. solani pathogens: The fungicide, botanicals and biocontrol agents found effective in vitro was evaluated in field for management of root rot ashwagandha. The plots size was 4 × 2 meter ( $8 \mathrm{sqm})$ in randomized block design (RBD) three replication of each treatment were maintained. Total 14 treatments were taken including control. For the field experiment cultures of $F$. solani and $R$. solani were reportedly on corn meal-sand (1:1) medium. This mixture was filled in $500 \mathrm{ml}$ flasks to about $2 / 3^{\text {rd }}$ of the capacity. The flasks were autoclaved for one hour at $1.056 \mathrm{~kg} / \mathrm{cm}^{2}$ pressure twice and inoculated with $R$. solani and $F$. solani incubated at 28 $\pm 2^{\circ} \mathrm{C}$ for 10 days. Inoculated flasks were shaking daily to avoid clumping. Mycelium growth and profuse sporulation of the pathogens occurred on the media after 10 days and then mixed in to the soil for multiplication of the pathogen. All the plots were lightly irrigated immediately after inoculation and to allow establishment of the pathogen before sowing. For comparison two controls were kept. In one control, plots had inoculated soil and another set of control plots had sterilized soil without inoculation. For each treatment and control three plots with three replications were maintained.

Treatment with cake, neem formulation, biocontrol agent and fungicide (integrated management): Fungicides and biocontrol agents found effective in vitro were evaluated individually and in combinations Seed treatment with SAAF (Carbendazim 12\% + Mancozeb 63\% WP)

Seed treatment with Neem oil

Seed treatment with $T$. viride ICRISAT

Soil application of Neem cake

Seed treatment with SAAF + Neem oil

Seed treatment with $\mathrm{SAAF}+T$. viride ICRISAT

Seed treatment with Neem oil $+T$. viride ICRISAT

Seed treatment with $\mathrm{SAAF}+\mathrm{Neem}$ oil $+T$. viride ICRISAT

Soil application of Neem cake + Neem oil

Soil application of Neem cake + SAAF

Soil application of Neem cake $+T$. viride ICRISAT

Soil application of Neem cake $+\mathrm{SAAF}+T$. viride ICRISAT

Inoculated untreated control.

Uninoculated untreated control

For seed treatment, cultures of the bio-control agents were individually grown on $2 \%$ malt extracts agar (MEA). The sporulatings colonies were harvested by suspending in $20 \mathrm{ml}$ water in each Petri dish and mixed with sterilized fine clay (talc powder) 10 gm to make a slurry. These formulations of the individual BCA's were used for seed treatments@10 g/kg seed. The coated seeds were kept overnight in moist chamber so as to enable the antagonists to establish on seeds and for chemical/botanical seed treatment, small quantity of each fungicide/botanical were used and seeds were soaked in fungicide SAAF $75 \mathrm{WP}(0.20 \%)$ and botanical Achook (3\%) separately for 30 minutes, air dried in shade and sown.

Per cent root rot $=\frac{\text { Total number of infected plants }}{\text { Total number of plants assessed }} \times 100$

\section{RESULTS AND DISCUSSION}

Evalution of integrated disease management modules against root rot of Ashwagandha: Based on in vitro studies, the effective botanicals (Neem oil) and bicontrol agent (Trichoderm viride, take based formulation) and fungicide SAAF were soil application of neem cake manure evaluated individually as well as in various combination in a sick plot (infected with $F$.solani and $R$. solani) for management of ashwagandha root rot (Table 1).

In the field trial conducted in the sick plot, high plant mortality was observed in the untreated control plots .In the inoculated control, mortality was $88.9 \%$ while in the uninoculated control, it was $70.4 \%$ the seed treatment with SAAF and Trichoderma formulation and Neem cake manure resulted in $32.2 \% 49.3 \%$ and $30.3 \%$ mortality, respectively, while plots having seed treatments with Neem oil showed $64.7 \%$ mortality. Sinha and Padamini (2015) studied effect of volatile and non-volatile compounds produced by native Trichoderma spp. on $R$. solani causing sheath blight of rice in Manipur The results showed that all the isolates of Trichoderma spp. have potential to inhibit the mycelial growth of $R$. solani. The volatile compounds produced from the nine Trichoderma isolates showed inhibition of 35.33 to $79.53 \%$ of mycelial growth of $R$. solani. Combined treatment resulted in considerably reduced mortality, and with SAAF and Neem oil resulted in $36.0 \%$ mortality, Seed treatment with Neem oil $+T$. viride also was at per showing $35.7 \%$ mortality. Combination of three treatments further reduced the plant mortality due to $F$. solani and $R$. solani. The lowest mortality $(11.8 \%)$ was in combined treatment having $\mathrm{ST} \mathrm{SAAF}+T$. viride and soil application of Neem cake. This was closely followed by ST SAAF + soil application of neem cake which had $17.9 \%$ mortality. Next effective was the treatment having ST T. viride + soil application of Neem cake, where $23.7 \%$ mortality was recorded. Dhingani et al (2013) studied four organic extracts were tested against $M$. phaseolina by poisoned food technique in vitro. Significantly least growth of mycelium and maximum mycelium inhibition was recorded in extracts of neem cake $(59.40 \%)$ followed by farm yard manure $(42.56 \%)$. Next best in order of merit were castor cake and mustard cake. The difference in percent in mortality among these three treatments were statically significant. In the un-inoculated control plots 
the root yield was $125 \mathrm{~g} / \mathrm{plot}(2.5 \mathrm{q} / \mathrm{ha})$ seed yield was $65 \mathrm{~g}(1.30 \mathrm{q} / \mathrm{ha})$, root length $12.5 \mathrm{~cm}$, root diameter $2.93 \mathrm{~mm}$ and alkaloids $0.47 \%$. In the inoculated control ashwagandha plots, yield was $75 \mathrm{~g}(1.5 \mathrm{~g} / \mathrm{ha})$, $20 \mathrm{~g}(0.40 \mathrm{q} / \mathrm{ha})$, root length $10.38 \mathrm{~cm}$, root diameter $2.40 \mathrm{~mm}$ and alkaloids $0.32 \%$. All the treatment resulted in increased dry root and seed yield and the alkaloids contents highest root yield $345 \mathrm{~g} / \mathrm{plot}$ enhanced root parameters and $(6.90 \mathrm{q} / \mathrm{ha})$ was obtained with combined treatment of ST SAAF $+T$. viride and soil application of Neem cake the seed yield in this was $292 \mathrm{~g} /$ plot $(5.83 \mathrm{q} / \mathrm{ha})$ mean root length was 22.1 $\mathrm{cm}$, root diameter 6.53 and alkaloids content $0.74 \%$. In second best treatment ashwagandha plots (ST SAAF + soil application of neem cake. The dry rot root yield was $330 \mathrm{~g} / \mathrm{plot}(6.6 \mathrm{q} / \mathrm{ha})$, seed yield was $270 \mathrm{~g} /$ plot $(5.40 \mathrm{q} / \mathrm{ha})$, root length $21.47 \mathrm{~cm}$, root diameter $6.30 \mathrm{~mm}$ and alkaloid content $0.73 \%$. In treatment having ST T. viride + soil application of Neem the root yield was $310 \mathrm{~g} / \mathrm{plot}(6.20 \mathrm{q} / \mathrm{ha})$, seed yield was $250 \mathrm{~g} /$ plot $(5.0 \mathrm{q} / \mathrm{ha})$, root length was 21.30 $\mathrm{cm}$ root diameter $6.27 \mathrm{~mm}$ and alkaloid $0.66 \%$.

In brief, all the remaining treatment resulted in root yield ranging from(173-300) g/ plot (3.50-6.0 $\mathrm{q} / \mathrm{ha})$ seed yield ranging from $115-243 \mathrm{~g} / \operatorname{plot}(2.30-4.87 \mathrm{q} / \mathrm{ha})$, root length $15.73-21.47 \mathrm{~cm}$, root diameter $5.32-6.0 \mathrm{~mm}$ and alkaloid content ranging from $(0.48-0.66 \%)$ in ashwagandha plots. In these parameter also, the combined treatments was better effective than the individual ones.

In the three best treatments, the alkaloid content was 1.8-2.3, times higher than control (Table 1). In the three best effective treatments the roots yield was four time higher seed yield was 30 times, root length was two times, root diameter. 2.6 time and alkaloid content was 2.3 times higher over the inoculated control, and $2.7,4.5,1.8$, and 1.8 times high over the uninoculted control. The fungicides, oil cakes, neem formulation and bio-control agents which were found effective in vitro, were further evaluated as seed treatment individually as well as in different combination for suppression of Ashwangadha root-rot in field conditions. In this experiment, two types of controls were maintained inoculated and uninoculated. In uninoculated control also, considerable disease severity occurred, as it was a sick plot where Ashwagandha was being grown for two kharif season. But to ascertain adequate disease pressure moderate level of inoculum was added, hence disease and population density of both the pathogens was higher in the inoculated control over the uninoculted one. In the field trial, integrated treatment $(\mathrm{ST} \mathrm{SAAF}+$ Neem cake $+T$. viride) showed minimum per cent root rot, maximum per cent germination and maximum yield of Ashwagandha. The different methods of application of fungicides and biocontrol agents, seed treatments have been most favoured and used, and there are several studies to show that the BCAs applied on seed can 
establish in the rhizosphere and provide good suppression of the pathogens and diseases (De and Mukhopadhyay, 1990, Vyas, 1994 and Xue et al 2007). Gyanendra and Verma (2005) reported good compatibility of fungicides carbendazim, Neem products and biocontrol agents ( $T$. harzianum and $T$. viride), for control of soybean root-rot. It was observed that integrated treatments were more effective over their individual applications as well as over the untreated control. Similar results on integration of fungicides with BCAs have been observed by Mousa (1996), who reported $T$. viride and T. harzianum with carbendazim were found effective for reduction of $F$. solani and $R$. solani and good compatibility of fungicides carbendazim, neem products and biocontrol agents ( $T$. harzianum and $T$. viride) for the control of $F$. solani and $R$. solani causing root rot complex of soybean. Jatav and Mathur (2005) and Tetarwal (2011) studied that BCAs and two neem formulations with carbendazim and Tebuconazole were highly effective against $R$. solani and $F$. solani (root-rot complex in cluster bean and soybean).

\section{Conclusion}

The experiment was conducted to study fungicides, biocontrol agents and botanicals for management of ashwagandha root rot caused by two pathogen $F$. solani and $R$. solani. In the inoculated control, mortality was $88.9 \%$ while in the uninoculated control, it was $70.4 \%$ the Seed treatment with SAAF and Trichoderma formulation and Neem cake manure resulted in $32.2 \% \quad 49.3 \% \quad 30.3 \%$ mortality, respectively, while plots having seed treatments with Neem oil showed $64.7 \%$ mortality. Combined treatment resulted in considerably reduced mortality, and with SAAF and Neem oil resulted in $36.0 \%$ mortality, Seed treatment with Neem oil + T.viride also was at per showing $35.7 \%$ mortality. Combination of three treatment further reduced the plant mortality due to F.solani and R.solani. The lowest mortality $(11.8 \%)$ was in combined treatment having ST SAAF $+T$. viride and soil application of Neem cake. In the un-inoculated control plots the root yield was $125 \mathrm{~g} /$ plot $(2.5 \mathrm{~g} / \mathrm{ha})$ seed yield was $65 \mathrm{~g}(1.30 \mathrm{~g} / \mathrm{ha})$, root length $12.5 \mathrm{~cm}$, root diameter $2.93 \mathrm{~mm}$ and alkaloids $0.47 \%$. In the inoculated control, these value was $75 \mathrm{~g}$ $(1.5 \mathrm{~g} / \mathrm{ha}), 20 \mathrm{~g}(0.40 \mathrm{q} / \mathrm{ha})$, root length $10.38 \mathrm{~cm}$, root diameter $2.40 \mathrm{~mm}$ and alkaloids $0.32 \%$. All the treatment resulted in increased dry root and seed yield and the alkaloids contents highest root yield $345 \mathrm{~g} / \mathrm{plot}$ enhanced root parameters and $(6.90 \mathrm{q} / \mathrm{ha})$ was obtained with combined treatment of ST SAAF $+T$. viride and soil application of Neem cake the seed yield in this was $292 \mathrm{~g} / \mathrm{plot}(5.83 \mathrm{~g} / \mathrm{ha})$ mean root length was 22.1 $\mathrm{cm}$, root diameter 6.53 and alkaloids content $0.74 \%$. In second best treatment (ST SAAF + soil application of neem cake. The dry rot root yield was $330 \mathrm{~g} / \mathrm{plot}$ (6.6 q/ha), seed yield was $270 \mathrm{~g} /$ plot $(5.40 \mathrm{q} / \mathrm{ha})$, root length $21.47 \mathrm{~cm}$, root diameter $6.30 \mathrm{~mm}$ and alkaloid content $0.73 \%$. As such, the treatments found effective in sick plot conditions seem to be promising for practical disease management in farmer's field also. Consequently, integration management appeared not only economical but eco-friendly strategy for better control of root rot of Ashwagandha.

\section{REFERECES}

Anabalagan, K. and Sadique, J. (1984). Role of prostaglandins in acute phase proteins in inflammation. Biochem. Med., 31: 236-245.

Anonymous. (1976). The Wealth of India, (Raw Materials); CSIR: New Delhi, India. 10 : 580- 585. England.16pp

Baghel, G., Jahan, T., Afreen, B., Naqvi, Q.A., Snehi S.K., and Raj, S.K. (2010). Detection of a begomovirus associated with yellow mosaic disease of Ashwagandha (Withania somnifera L.) and its impact on biomass yield. Medicinal Plants, 2(3) :219-223

Begum, V.H. and Sadique, J. (1988). Long term effect of herbal drug Withania somnifera on adjuvant induced arthritis in rats. Indian J. Exp. Biol., 26(11): 877-882

Bhattacharya, S.K., Bhattacharya, A., Sairam, K. and Ghosal, S. (2000). Anxiolytic- antidepressant activity of Withania somnifera glycowithanolides: an experimental study. Phytomedicine, 7(6): 463-469.

Booth, C. (1971). The genus Fusarium. Commonwealyh Mycological Institute, Kew,

Davis L. and Kuttan G. (2000). Immunomodulatory activity of Withania somnifera. J. Ethnopharmaol, 71 (1-2): 193 -200 .

De RK and Mukhopadhyay A. (1990). Control of dampingoff in tomato by seed coating with Gliocladium virens. Proc. Int. Conf. Seed Sci. Technol. New Delhi. 120 pp.

Dhingani, J. C., Solanky K. U. and Kansara, S. S. (2013). Management of root rot disease [Macrophomina phaseolina (tassi.) Goid] of chickpea through botanicals and oil cakes. The Bioscan, 8(3): 739-742.

Dhuley, J.N. (1998). Effect of Ashwagandha on lipid peroxidation in stress-induced animals. $J$. Ethnopharmacol, 60 (2): 173-178.

Gyanendra S and Verma RK .2005. Compatibility of fungicides and Neem Products against Fusarium solani f.sp. glycines causing root-rot of soybean and Trichoderma spp. Journal of Mycological Research 43: 211-214.

Jatav, R. S. and Mathur, K. (2005). Bio-agents and neem based seed treatment for management of root-rot complex in cluster bean. Indian Phytopathology, 58: 235-236.

Mordue, J. E. M. (1988). International course on the identification of fungi and bacteria of agriculture importance. Commonwealth Mycological Institute, 69: 102-116.

Mousa, E. S. M. (1996). Biological management of soilborne pathogens and root knot nematode complexes on soybean (edited by Mousa, E.S.M.). ShebinEiKom Egypt, Menoufiya University, 60-69.

Singh S. and Kumar S. (1998). Withania somnifera: The Indian ginseng Ashwagandha, Central Institute of Medicinal and Aromatic Plants, Lucknow, India.

Sinha, B. and Padamini, R. K. (2015). In vitro study of Trichoderma spp. Against sheath blight of rice caused by Rhizoctonia solani in Manipur. The Ecoscan. 9: 295298. 
Sharma, R. (2004). Agro-Techniques of Medicinal Plants. Daya Publishing House: New Delhi, India, pp. 31-33.

Tetarwal, J. P. (2012). Mix mycelia of F. solani and R. solani causing root rot of soybean M.Sc. Thesis, MPUAT, Udaipur (Rajasthan)

Vyas, S. C. (1994). Integrated biological and chemical control of dry root-rot on soybean. Indian $\mathrm{J} \mathrm{Mycol} \mathrm{Pl}$
Pathol. 24: 132-134.

Xue, A.G., Cozber, E., Morrison, M.J., Voldeng, H.D. and Ma, B.L. (2007). Effect of seed treatments on emergence, yield and root-rot severity of soybean under Rhizoctonia solani inoculated field conditions in Ontario. Canadian Journal of Plant Science 87: 167173. 